\title{
The Physical Safety and Security Features of U.S. Hotels
}

by CATHY A. ENZ

The physical attributes or features that signal safety and security are a critical part of the overall "servicescape" of a hotel and help to define the service experience. An investigation of the safety and security features of 5,487 U.S. hotels revealed significant differences in the distribution of these key amenities in various hotel price segments. Differences in these physical attributes were also found among hotels of various sizes, ages, and locations (e.g., urban, airport, small town). Analyzing hotel scores across several different categories revealed an average safety index score of 70 and a security index score of 64 out of a possible score of 100. Overall luxury and upscale hotels, newer hotels, larger hotels, and those located in urban and airport locations recorded the highest scores for safety and security. Using partial correlation analysis, safety and security scores were positively correlated with the published rate of the hotels, even when controlling for hotel size, age, location, and price segment, suggesting that offering more comprehensive physical safety and security features is associated with the advertising of a higher rate.

Keywords: hotel safety; hotel security

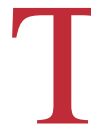
The tragic attacks on hotels in Mumbai in November 2008 and Jakarta in July 2009 are recent reminders of the vulnerability of hotels to potential safety and security threats. The continuous flow of people in and out of a hotel makes it a "soft target" for harm and poses a challenge to the property's security and to the safety of the people in that hotel (Hennelly 2008). Preserving customer service standards and ensuring safety in the quasi-public spaces of hotel buildings is challenging since it is often difficult to distinguish among guests, legitimate visitors, and people who are potential threats. Moreover, hoteliers find it awkward to maintain the 
highest possible standards of safety while preserving a hotel's hospitable and welcoming image.

The physical attributes or features that signal safety and security are part of the overall "servicescape" or physical elements of a consumption setting and help to define the service experience (Hilliard and Baloglu 2008; Hoffman, Kelley, and Chung 2003; Bitner 1992). Visible safety features and safety documentation have been found to play a key role in shaping meeting planners' site-selection choices (Hilliard and Baloglu 2008). Others have reported that safety and security attributes vary with the age of a hotel, its geographic location, and the market segment (Enz and Taylor 2002). Furthermore, travelers report a willingness to pay more if safety and security features are provided, suggesting that managers may obtain a return on their investments for offering these hotel attributes (Slevitch and Sharma 2008; Feickert et al. 2006).

The study reported here investigates the degree to which hotels vary in their visible safety and security features and the impact of this variation on the average rack rate that can be advertised for hotel products. While the words safety and security are often used interchangeably, the two concepts differ in their focus. Safety involves protecting employees and customers within the hotel property from potential injury or death. Thus, safety issues deal with the effects of accidents, hazardous materials, and fire (Ellis and Stipanuk 1999). In addition to the safety issues, hotel security goes beyond protecting employees and guests and is also concerned with preserving guests' possessions and the property itself. Security issues involve such matters as theft and violent crime. Indeed, some experts include safety as a category of security issues. Following the distinctions offered by the experts, this article treats safety as a particular form of security that focuses on the protection of guests from injuries (whether from accidents or criminal activity).

\section{The Study}

The data used in this study were drawn from the American Hotel and Lodging Association's (AH\&LA) 2008 Lodging Survey, which is distributed annually to general managers throughout the United States. All hotels in the United States, including those of non-AH\&LA members, are given the opportunity to participate in the survey. The survey was distributed to 45,000 properties and reported a response from 8,448 hotels, of which 5,487 questionnaires were complete for all of the relevant security questions.

Safety equipment includes items such as sprinklers, smoke-free guest rooms, security cameras, and guest-safety instructions; while security features include electronic locks, in-room safes, interior corridors, and safety materials. The study employs two indexes, one measuring safety amenities and the other gauging security equipment. The safety and security indexes created for this study were based on those I used with Masako Taylor in a previous examination of this topic (Enz and Taylor 2002). However, I modified the indexes to reflect the changes in the 2008 Lodging Survey.

While the inventory of various physicalsafety and security features is by no means exhaustive, it does reflect key safety issues. I must also note that the mere presence of such equipment as electronic locks and security cameras does not guarantee guests' safety or security in the absence of personnel who are well trained to implement a fully developed emergency plan. On the other hand, a hotel would be hard-pressed to implement an effective security system in the absence of appropriate equipment.

Because some features are more important than others are to a hotel's (and guests') safety and security, each feature 
was weighted on its relative importance, based on consultation with hospitality industry property management experts and the existing literature that distinguishes which elements are of key importance. The two indexes (that is, for safety and for security) were created by assigning weights to the two sets of items. Greater weight was accorded in the safety index to sprinklers, for instance, than to safetyinstruction materials, such as in-room safety videos. In the security index, electronic locks received the greatest weight, while security cameras and interior corridors earned lower weights.

\section{Results}

The higher the hotel's score on each index, the greater the level of its safety and security equipment. The average safety index score for our sample is 70 percent, compared to a possible perfect score of 100 percent if all the safety and security features listed in the 2008 lodging survey were present in a hotel. The average security index score is 64 percent. These numbers suggest that U.S. hotels score generally higher on physical-safety attributes than they do on the broader security features that include both protecting individuals (safety) and also safeguarding their possessions. The standard deviation for the safety index was 23.3 , while the standard deviation for the security index was 20.2 . These relatively large deviations suggest considerable variation across hotels in their safety and the security efforts. I found a strong correlation between a hotel's location and the extent to which it has safety and security features. Urban, suburban, and airport hotels appear to score higher on safety and security than do hotels located along highways, in resorts, or in small metropolitan areas, as shown in Exhibit 1. The lowest scores are found for hotels in small towns.
A one-way analysis of variance test for the mean differences in safety and security scores across location revealed statistically significant differences for both security $(F=79.55, p<.001)$ and safety $(F=$ 137.46, $p<.001)$. While this analysis reveals that hotels in diverse locations operate with different levels of risk, it is interesting to note that perceived risks may be higher in airport and urban areas than they are in small towns or resort locations. Thus, it is important for big-city hoteliers to provide additional physical features in the servicescape to offer reassurance to their guests.

The servicescapes of higher-end hotels often appear to be more secure and safe than those of lower-end hotels. To explore whether hotels differ on safety and security based on price segment, I conducted an analysis of variance test on the different hotel price segments. The results reveal that security $(F=73.31, p<.001)$ and safety features $(F=265.13, p<.001)$ do vary by hotel price segment. Exhibit 2 shows the mean scores by price segment. The survey revealed that the highest safety and security scores are for luxury hotels and that progressively fewer safety and security features are present in the lowerprice segments. Thus, the perception that higher-price hotels contain more physical safety and security features than hotels in other price segments is not surprising, because it is accurate.

Two additional attributes, the size and the age of the hotel, might explain the variation in the presence of safety and security features. Smaller and older hotels may invest in fewer features, reflecting the costs of modifying current facilities or decisions to conserve financial resources. As Exhibits 3 and 4 show, larger and newer hotels tend to have higher scores on both the safety and the security indexes than do their smaller and older competitors. One-way analyses 


\section{Exhibit 1:}

Mean Safety and Security Index Scores by Location

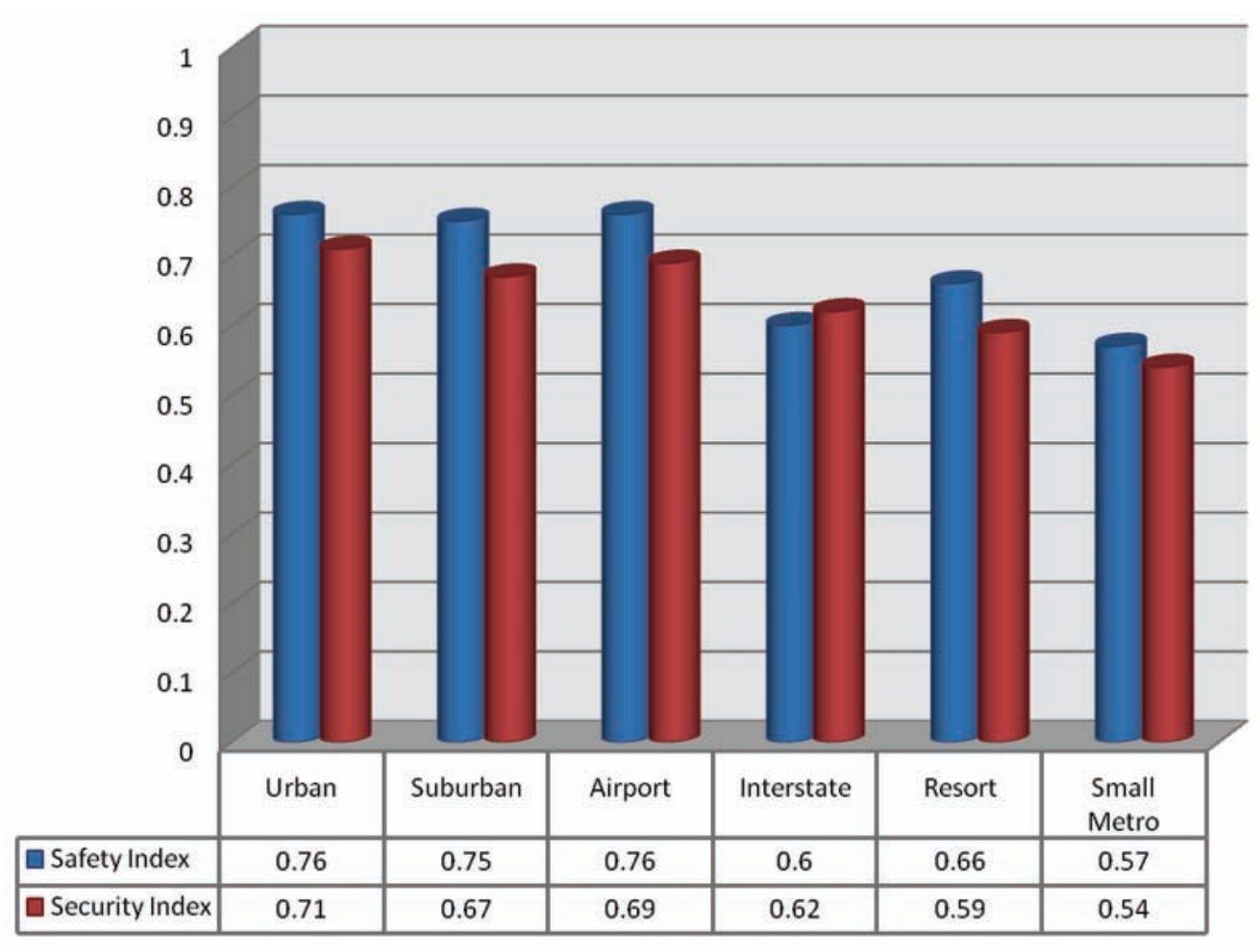

of variance reveal that significant differences exist on these indexes across age and size of hotel. Hotels with fewer than sixty-four rooms score substantially lower on the safety index than do hotels with a higher room count. Regarding the security index, by contrast, the dividing point seems to be fifty rooms. Hotels with between fifty and sixty-four rooms are more akin to larger hotels on the security index, while hotels with less than fifty rooms score far lower on security than any other group of hotels did. New hotels (less than eight years old) offer the most comprehensive array of safety and security amenities, but lower scores are most notable for the oldest hotels in the sample (thirty years or older). Next, let us consider whether safety and security features are positively related to hotel rates, defined as the average rack rate for a standard room with single occupancy.

The Relationship of Hotel

Security to Advertised

Room Rates

I tested the relationship between a hotel's safety or security index and the price it asks by examining the correlation between safety and security indexes and the average rack rate of hotels (controlling for the hotel price segment). I used rack rate of the hotels even though these published rates are often set artificially high. They are, nevertheless, used as a reference point for calculating a variety of discounts. I would have preferred to apply average daily rate, but those data were not available. Since higher-end hotels are likely to 
Exhibit 2:

Mean Safety and Security Index Scores by Hotel Price Segment

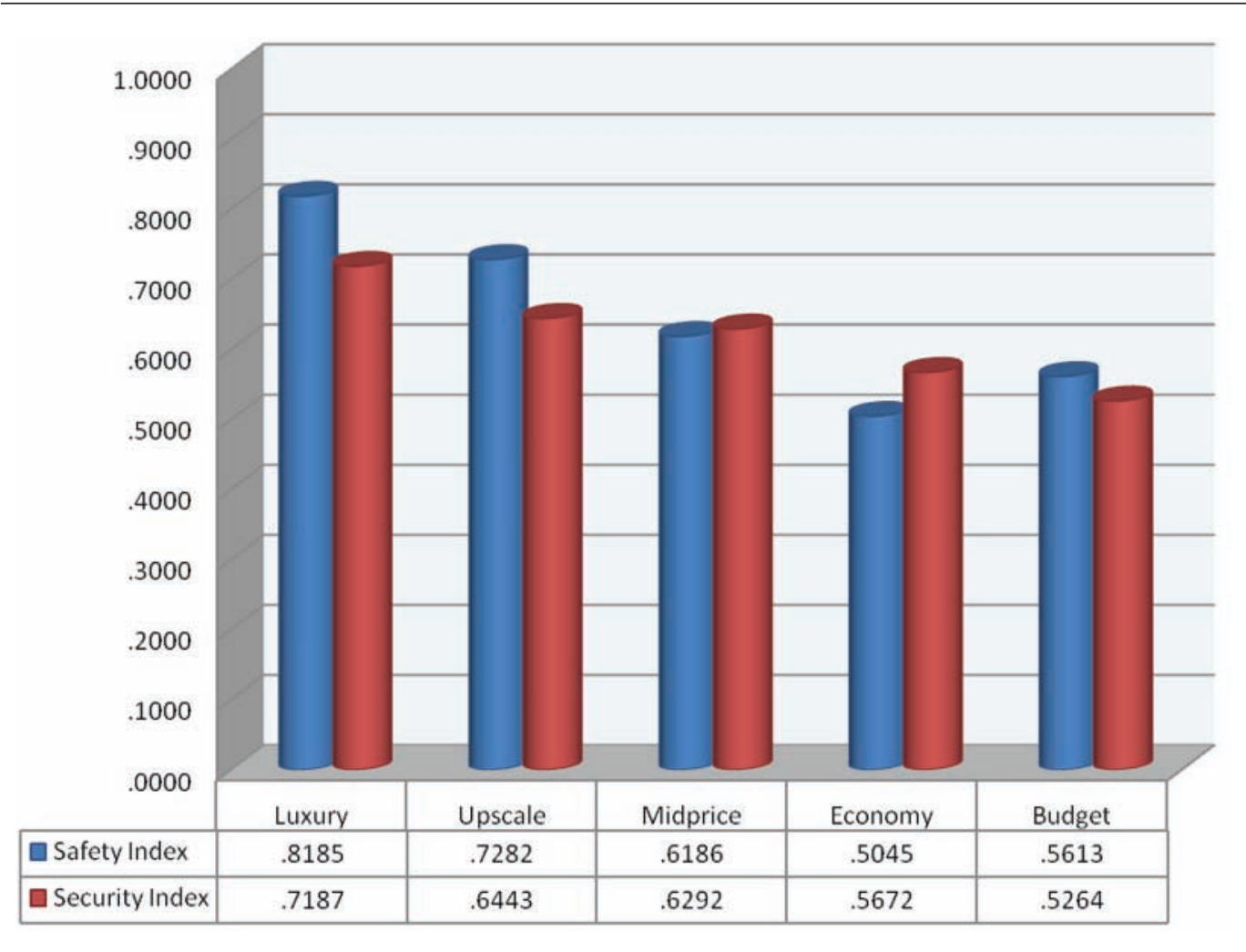

offer a higher published rate and also score higher in safety and security, to explore fully the linkage between these indexes and rate, the hotel price segment was held constant. The results of partial correlation analysis which controlled for variation due to a hotel's price segment revealed that the safety index $(r=.098, p<.001, n=4,353)$ and security index $(r=.110, p<.001)$ were both positive and significantly related to the average published rate of the hotel. Further investigation controlling for location type (e.g., urban, airport, resort) and region of the United States also revealed positive and significant relationships between the published rate of a hotel room and the degree to which the hotel has safety and security features (see Exhibit 5). The final analyses reported in Exhibit 5 presents the significance of the partial correlations between the indexes and average rack rate controlling for the effects of hotel size and age, along with that for segment and location. Again the data show that published price and the degree of safety and security features are correlated; when factoring out the influences of hotel age or size, both factors that determine safety and security levels of hotels.

\section{Conclusion: Safety} and Security Pays

The safety and security indexes offer a preliminary glimpse into the elements of the servicescape that signal comfort and security to the guest. The results reveal that hotels are significantly different in the degree to which they have invested in 


\section{Exhibit 3:}

Mean Safety and Security Index Scores by Number of Rooms

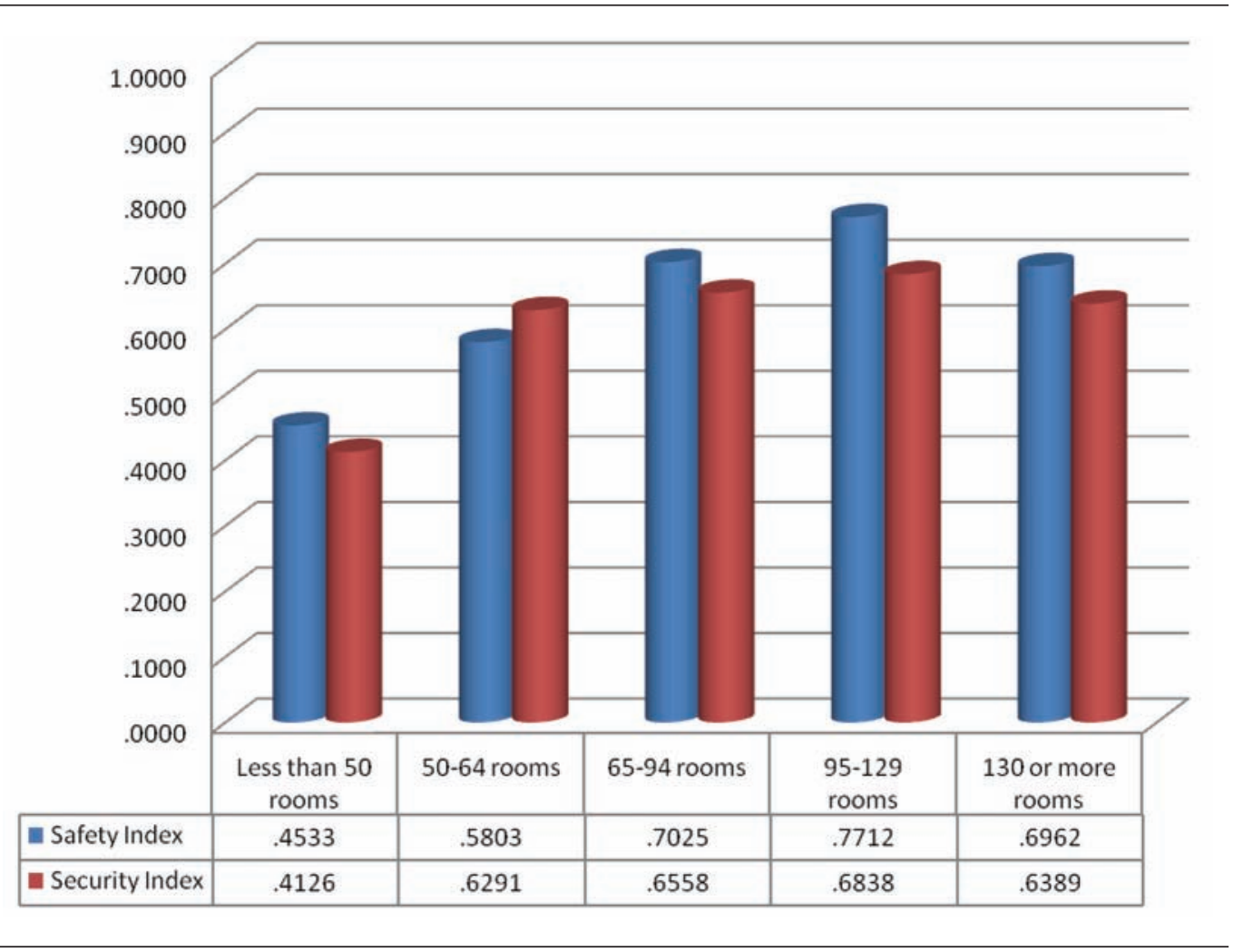

these features to protect guests and employees and to provide a secure environment. While the indexes focus on the existence of various features and not on the effectiveness of their use, the results do suggest that hotels vary significantly on the degree to which they have provided these physical features. Hotels in higher-end price segments and urban locations offer more features than do hotels in economy or budget segments in resort or small town settings. Larger and newer hotels are outfitted with features such as electronic locks, security cameras, sprinklers, and interior corridors that might be missing in lowerend or smaller properties. On balance, luxury and upscale hotels, airport and urban hotels, large properties, and new hotels are most likely to maintain a high level of safety and security amenities, a finding that replicates the study I conducted with Masako Taylor (Enz and Taylor 2002). In contrast, old, small, budget motels are the properties most challenged in providing those safety and security features in these studies.

Finally, strong correlations between safety and security amenities and average rack rate suggest that a price premium exists for hotels that offer these physical elements of the servicescape. The fact that some hotels score high on the indexes does not guarantee that they are physically safe and secure, but the results do suggest that a price premium (higher advertised rack rate) does appear to be associated with those hotels that offer a full complement of safety and security features. In 
Exhibit 4:

Mean Safety and Security Index Scores by Hotel Age

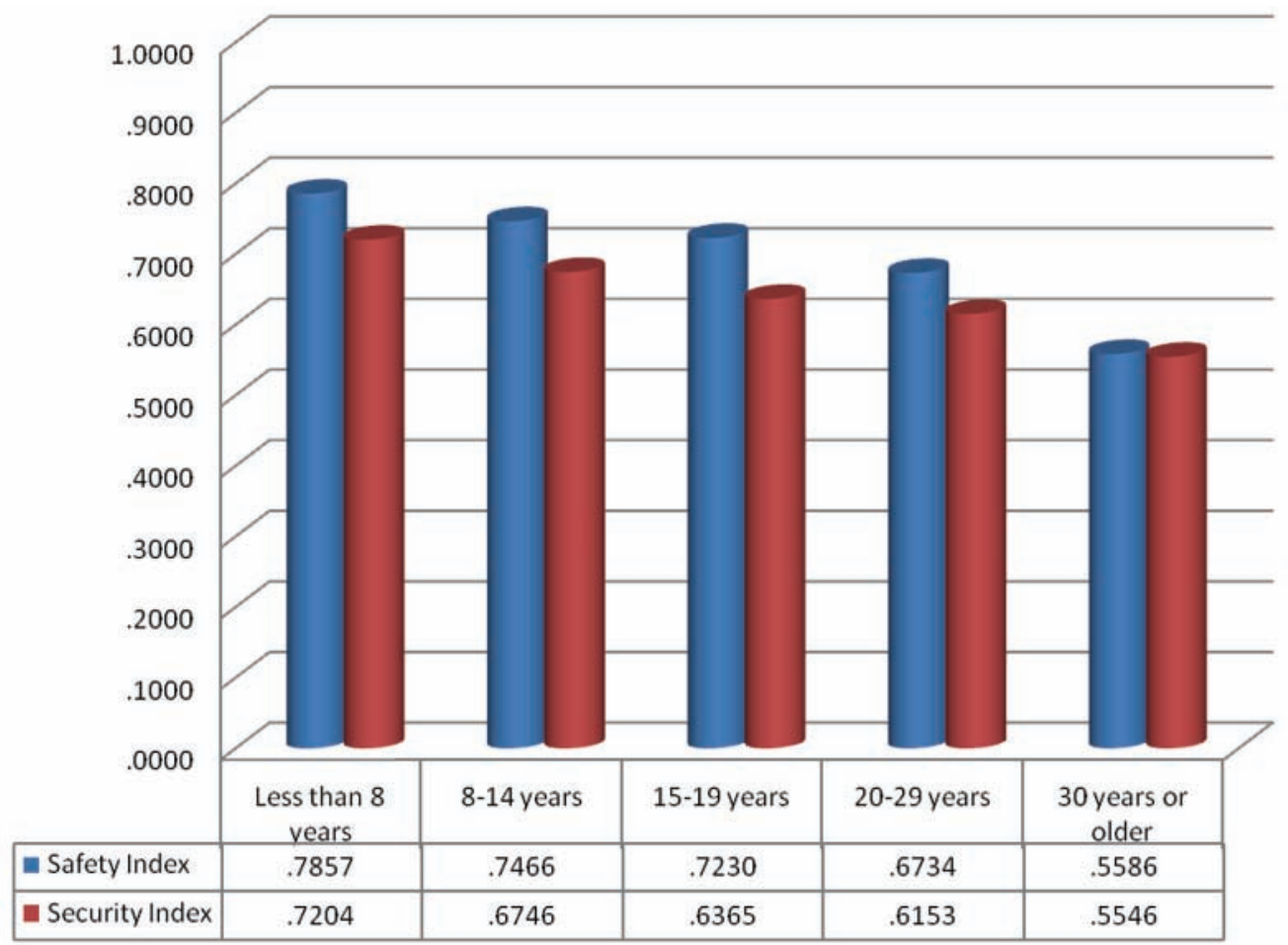

Exhibit 5:

Partial Correlations between Safety and Security Indexes and Average Rack Rate $(N=4,352)$

\begin{tabular}{lcc}
\hline Average Rack Rate & Safety & Security \\
\hline Controlling for price segment & $r=.098, p<.001$ & $r=.110, p<.001$ \\
Controlling for location & $r=.238, p<.001$ & $r=.212, p<.001$ \\
Controlling for region & $r=.258, p<.001$ & $r=.233, p<.001$ \\
Controlling for size of hotel & $r=.203, p<.001$ & $r=.173, p<.001$ \\
Controlling for age of hotel & $r=.259, p<.001$ & $r=.229, p<.001$ \\
\hline
\end{tabular}

short, investing in the security of the guest does appear to have a monetary payoff.

\section{References}

Bitner, M. J. 1992. The impact of physical surroundings on customers and employees. Journal of Marketing 56 (2): $57-71$
Ellis, Raymond C., Jr., and David M. Stipanuk. 1999. Security and loss prevention management. East Lansing, MI: Educational Institute of the AH and MA.

Enz, Cathy A., and M. Taylor. 2002. The safety and security of U.S. hotels: A post September 11th report. Cornell Hotel and Restaurant Administration Quarterly 43 (5): 119-36.

Feickert, Julie, Rohit Verma, Gerhard Plaschka, and Chekitan S. Dev. 2006. Safeguarding your customers: The guest's view of hotel security. Cornell 
Hotel and Restaurant Administration Quarterly 47: 224-44.

Hennelly, B. 2008. How safe are hotels and other urban spaces? WNCY.Org. http://www.wnyc.org/news/ articles/118764 (accessed April 10, 2009).

Hilliard, Tyra W., and Seyhmus Baloglu. 2008. Safety and security as part of the hotel servicescape for meeting planners. Journal of Convention and Event Tourism 9 (1): 15-34.
Hoffman, K. D., S. W. Kelley, and B. C. Chung. 2003. A CIT investigation of servicescape failures and associated recovery strategies. Journal of Services Marketing 17:322-40.

Slevitch, Lisa, and Sharma Amit. 2008. Management of perceived risk in the context of destination choice. International Journal of Hospitality and Tourism Administration 9 (1): 85-102.

Cathy A. Enz, Ph.D., is Lewis G. Schaeneman, Jr. Professor of Innovation \& Dynamic Management at the Cornell University School of Hotel Administration (cae4@cornell.edu). 